\title{
HOMEM E MULHER OS CRIOU
}

\author{
Isabel Arco Verde Santos* \\ (Universidade do Estado do Rio de Janeiro)
}

RESUMO: O presente artigo retoma os textos da criação e reflete, reflete, especificamente na criação da mulher. Os termos hebraicos que acompanham a narrativa da criação e se relacionem com a figura feminina, têm muito a nos contar. Afinal, qual o papel da mulher e seu objetivo ao ser criada, frente ao homem? Haveria uma clara dimensão de superioridade ou inferioridade refletidas nestes relatos? Em nossa sociedade de cultura cristã, o texto bíblico tem valor imensurável na relação de gênero que vivemos em nossa sociedade. Voltar o olhar ao texto bíblico e buscar nele caminhos a partir da crítica textual, é uma forma de buscar respostas para diminuir as injustiças que separam homens e mulheres.

PALAVRAS-CHAVE: relatos de criação; relação homem mulher; Eva e Lilith

\section{MALE AND FEMALE CREATED HE THEM}

\begin{abstract}
This article analyzes the Hebrew texts of creation and reflects, specifically on the creation of women. The Hebrew terms that accompany the creation narrative and relate to the female figure have much to tell us. What is the function of women and their purpose when being created? Would there be a clear dimension of superiority or inferiority between men and women reflected in these texts? In our Christian culture society, the biblical text has immeasurable value in the gender relationship we live in our society. Turning to the biblical text through textual criticism is a way of seeking answers to reduce the injustices that separate men and women.
\end{abstract}

KEYWORDS: creation texts; men and women relationship; Eva and Lilith

Nosso objetivo, neste primeiro momento é tratar do texto da criação do homem e da mulher. Este texto é básico para qualquer discussão. Os textos que iremos usar encontram-se todos no livro de Bereshit, ou Gênesis. É o primeiro livro da Torah, ou Pentateuco e traz nos seus primeiros capítulos o relato da criação.

É possível identificar dois relatos diferentes para esta história. Histórias de enfoques diferentes e origens também diferentes. O primeiro encontra-se em Gênesis 1:26-31. O segundo, no capítulo 2:15 a 24 deste mesmo livro. Ambos tratam da criação do ser humano: homem e mulher.

\footnotetext{
*E-mail: verdesantos@uol.com.br
} 
No primeiro texto, a designação hebraica usada para homem é zakhar ${ }^{1}$ e neqebah ${ }^{2}$ para a mulher. Estes termos indicam o que é masculino e o que é feminino, respectivamente. O termo para masculino é da mesma raiz do verbo lembrar, trazer a memória. O termo para feminino tem uma ideia mais ampla em sua raiz verbal, mas para o texto destaca-se a ideia de efeminar, tornar feminino.

Alguns autores interpretam a partir deste texto bíblico a criação de um ser andrógino. Adão, o primeiro homem seria, ao mesmo tempo, homem e mulher, isto porque, no relato, no verso 26 primeiramente acontece o termo Adam, sem artigo e sem a partícula acusativa, o que indicaria a criação da humanidade, uma coletividade, o chamado Adão primordial ${ }^{3}$. Assim, este verso no português ficaria: E disse Deus, façamos (a) humanidade com nossa imagem e semelhança.

No verso 27, quando Deus abençoa a criação desta humanidade, o termo Adam vem agora acompanhado de artigo HaAdam e da partícula acusativa. Aqui, como há o artigo antes do nome Adam, entendemos que não só o ser denominado Adão está sendo abençoado, pois em hebraico o artigo nunca ocorre antes de nome próprio, mas uma indicação definida daquilo que se está abençoando. Não um ser humano qualquer, mas o ser humano criado.

O texto pode ser traduzido, então, assim: E abençoou Deus o ser humano com sua imagem. Com imagem de Deus o criou (ser humano - refere-se ao termo masculino HaAdam), macho e fêmea os criou. A ideia andrógina seria difícil de contestar caso o pronome que sucede o verbo criar no estivesse no plural. Criou a eles e não a ele. A ordem divina entende que o domínio sobre a criação é dado indiferentemente a Adão, ao ser humano (bom enfatizar, sem o artigo definido), subentende-se assim uma não discriminação na ordem. Ela é dada ao ser humano e não exatamente a Adão - o primeiro homem -, visto que a partícula acusativa (Aleph/taw) não ocorre.

Vale ainda salientar que a dimensão da bênção de Deus sobre Adão, primeiramente, e ressalvada a bênção sobre macho e fêmea, sobre homem/mulher, se concretiza em ser a imagem de Deus. No verso 26 do capítulo primeiro, há o movimento de criação da humanidade - do ADAM sem artigo. Este é criado à imagem e semelhança de Deus. No verso 27, Deus abençoa Adão - o homem específico, o homem criado - com sua imagem. No verso 28, a bênção se esclarece estendida sobre homem e mulher.

A ausência ou presença da partícula de objeto direto ('et - aleph/taw) é de suma importância no estudo do texto, isto porque ela ocorre indicando o objeto direto quando este é especificado com o artigo, ou quando ele, por si mesmo, como ocorre com qualquer nome próprio é especificado por natureza ${ }^{4}$.

Esta questão do artigo junto à palavra Adam merece um outro estudo e é preciso atenção ao analisar o termo nestes primeiros capítulos. No capítulo 3, por exemplo, Adam ainda aparece como nome plural (vide verso 17), designando um ser geral, não obstante, no verso 22 reaparece HaAdam, indicando uma especificação do termo, entendendo o ser homem, Adão.

\footnotetext{
${ }^{1}$ Zain/kaf/resh

${ }^{2} \mathrm{Nun} /$ qoph/beit

${ }^{3}$ Em primeiro lugar, três eram os gêneros da humanidade, não dois como agora, o masculino e o feminino, mas também havia a mais um terceiro, comum a estes dois, do qual resta agora um nome, desaparecida a coisa; andrógino era então um gênero distinto, tanto na forma como nome comum aos dois, ao masculino e ao feminino, enquanto agora nada mais é que um nome posto em desonra. (PLATÃO, 1991, p. 57-58).

${ }^{4}$ Esta partícula é muito importante na análise sintática da frase hebraica. No caso do verbo transitivo direito, ela ajuda a identificar o predicado.
} 
O texto da criação do homem e, mais objetivamente, da mulher ocorre no capítulo seguinte, em 2:15-24. O capítulo dois retorna à história da criação de forma resumida, dando mais atenção à criação do homem e da mulher. Na tradução de Almeida (A BÍBLIA..., 1958), o verso 15 se lê assim: Tomou, pois, o SENHOR Deus ao homem e o colocou no jardim do Éden para o cultivar e guardar. O termo traduzido aqui por homem é HaAdam, ou seja, o nome aparece com o artigo, o que se entende o nome do primeiro homem - Adão.

Não há exatamente uma sequência neste segundo relato. A narrativa da criação tão cuidadosa e minuciosa exposta no relato anterior, neste capítulo já não mais importa. No verso 18 , o comentário divino aponta para a preocupação com relação à solidão de Adam e a necessidade de fazer alguém, segundo tradução de Almeida, uma auxiliadora que lhe seja idônea. A aplicação do artigo aqui, no termo Adam, parece indicar algo mais específico, tendo em vista o autor deixar claro que ele, Adam, está só. A vocalização hebraica confunde, porque o termo que se usa no verso 20 do capítulo 2, ao dizer que não havia para Adam - e desta vez a vocalização sugere a inexistência do artigo - quem fosse ézer e néged.

Ocorre que, neste verso 20, aparece o termo LeAdam. Se a forma com artigo acontecesse, a contração do artigo com a preposição suporia a forma LaAdam. E, parece ser a forma mais correta de se ler o texto, dando continuidade a ideia que está sendo desenvolvida.

HaAdam - Adão - dá nome aos elementos da criação, mas é Adam - o nome geral, a humanidade - que não encontrou alguém para estar ao seu lado. De uma forma ou de outra, o que se quer é justificar o relato da criação da mulher. Os termos usados por Almeida, auxiliadora e idônea, traduzem o hebraico ézer e néged, respectivamente.

Ora, ézer é a palavra usada no conhecido Salmo 121 (Elevo os olhos para o monte, de onde me virá o socorro?). Ressalte-se que o socorro não é encontrado não em seres inferiores. O salmista eleva os olhos, busca acima de si o socorro. Isto deixa claro que não há qualquer tipo de inferioridade na criação da mulher.

O outro termo, néged, é uma preposição que pode ser traduzida por defronte de, em frente; contra; diante de; em oposição; defronte; comparado com. Como verbo, na forma simples, paal, significa ser contra, ou estar defronte. Na forma causativa, no hiphil, o verbo significa contar, revelar, dizer algo ainda não conhecido.

Estes termos vão reaparecer no verso 20, quando, após o homem ter dado nome a todos os seres, se conclui mais uma vez que não havia nada que lhe fosse ézer e néged. O hebraico nos aponta ideias mais fortes que a tradução de Almeida. No português, auxiliador tem a ideia de ajudante, assistente, conforme explica o Aurélio. Idôneo, tem o sentido de conveniente e adequado, ainda segundo este mesmo dicionário.

O que se procura na criação para HaAdam (Adão) é o seu oposto, o seu contrário, porque o objetivo é crescer e encher a terra. Por outro lado, procura-se algo que lhe venha socorrer em sua solidão. O interessante, porém, é que, embora se entenda néged como uma possibilidade contrária, porque há a necessidade de encher a terra, tanto este termo, como o termo socorro (ézer) não vêm em forma feminina, mas masculina, apesar de tanto este quanto aquele ter uma forma hebraica similar feminina (ezrah e negdah).

Se prosseguirmos a leitura, naquilo que seria o relato da criação da mulher, identificamos, que, após cair em sono profundo, Deus retirou uma costela de Adão para construir a mulher.

Três termos agora se encontram neste texto da criação: tzélem, a imagem de Deus com que a humanidade foi abençoada é o termo que associa a humanidade a Deus que ficou no capítulo primeiro; tzéla', a costela retirada de Adão que é a matéria da qual é feita a 
mulher. Por último, temos o termo 'étzem, que aparece na fala deslumbrada de Adão ao acordar de seu sono e ver a criação de Deus na forma da mulher, oriunda de sua costela.

O novo ser criado é denominado 'yshah. Sua denominação é da mesma raiz da palavra 'ysh, que quer dizer homem. Esta semelhança dos dois nomes demonstra o reconhecimento de si mesmo no outro ser criado. HaAdam reconhece a mulher como algo semelhante a ele daí o uso dos termos tsela e tselem (costela e osso). O termo 'étzem - semelhança - une em sua raiz os dois termos que identificam a mulher como parte da humanidade. HaAdam não a identifica como 'ysh, pois percebe que existem diferenças entre eles - afinal ela é seu contrário.

Este texto bíblico, como outros textos do Gênesis, tenta explicar criação de homem e mulher, como partes da humanidade. Sua preocupação em desenvolver uma narrativa que explique a criação da mulher se dá para que não se incorra no erro de ignorar que a mulher também é abençoada com a semelhança de Deus, corroborada na criação que se faz da mesma matéria.

Não há uma preocupação em inferiorizar a mulher. Embora HaAdam a tenha chamado de 'yshah, seu nome aparecerá somente no capítulo seguinte, após a expulsão do Éden, quando então ele a chamará de Chawav, ou Eva. Se há superioridade porque ele lhe dá um nome, esta superioridade é uma das consequências do que se denominou pecado e gerou a expulsão do paraíso.

Os relatos cabalísticos dão conta de criação de uma outra mulher. Esta ideia não só é desenvolvida pelos dois relatos de criação, mas também pela fala de HaAdam, quando desperta de seu sono. Ele diz, segundo a tradução que fazemos aqui do hebraico: e disse o homem, esta, desta vez, é osso dos meus ossos... ${ }^{5}$ Se desta vez HaAdam se identifica com algo na criação, talvez teria acontecido algo antes com o qual ele não teria se adaptado ou não se sentiria reconhecido.

Lilith é a mulher que domina e seduz HaAdam, que lhe aproxima de seus institntos. Chavah, a segunda mulher é a que gera e constrói a história. Na religião, a primeira é tida como a mulher que deve ser desprezada, apesar de figurar no imaginário masculino, pois retorna nos sonhos de Adão. Ela também retorna aos textos bíblicos, principalmente nos sapiencieais, mais especificamente no livro de provérbios, nos capítulos 1 a 9, quando se faz oposição entre a sabedoria e a ignorância, entre a mulher do povo e a estrangeira.

Chavah vive com esta sombra - a mulher principal para a sociedade, mas não nos desejos de seu marido. A presença de Lilith na cultura judaica não é única. Ela pode ser encontrada no épico de Gilgamesh, que data de 2000 a.E.C; na pseudoepígrafe denominada Testamento de Salomão, que data de 200 E.C.; no Talmud e no Alfabeto de Ben Sira ${ }^{6}$, do ano 800 de nossa era, aproximadamente. Alguns indicam haver menção também no livro bíblico de Isaías 34:14 (a palavra Lilith vem da raiz laylah, que significa noite).

Lilith teria sido criada tão bonita e interessante que logo arranjou problemas com o primeiro o homem. Ainda segundo a narrativa mítica, Eva foi criada para substituir Lilith. Eva seria o oposto de Lilith, por sua vez, reúne traços marcantes de obediência, boa imagem, companheira, submissa ao sacerdote, ao Pai e à Lei e por

${ }^{5}$ Cf. capítulo 2, versículo 23 do livro de Gênesis.

${ }^{6}$ Onde se tem o registro mais antigo sobre Lilith, datado entre os séculos VIII e X a.C, segundo Koltuv (1986). 
fim, também fonte de pecado e desobediência. (GOMES; ALMEIDA, 2019).

É importante também observar que o capítulo 2 de Gênesis, este que se propõe a recontar a criação focando a criação do homem e da mulher é um texto javista-eloísta. Observa-se que o capítulo primeiro do gênesis é notoriamente um texto eloísta. Já o capítulo 2 refere-se a deus com o tetragrama sagrado $(Y h w h)$ seguido da forma Elohim. O texto mistura então as duas fontes.

A conclusão de HaAdam não necessariamente afirma a lenda, mas abrem uma possibilidade neste sentido. O que se pode concluir é que não havia nada na criação com a qual ele, HaAdam, se identificasse.

A preocupação da leitura bíblica e as possíveis interpretações relacionando ao papel da mulher na sociedade ainda precisam ser mais bem resolvidas. Mesmo que se faça a presença de Lilith no texto, como a história omitida e não contada, porque precisava ser reescrita na forma de Chawah, ainda assim carece a ideia de submissão e inferioridade que culturalmente ainda se insiste afirmar.

O texto Eloísta que domina o capítulo primeiro do Gênesis não tem qualquer preocupação em distinguir homem e mulher. $\mathrm{O}$ capítulo segundo, na comunhão JavistaEloísta, tem a preocupação em frisar que são diferentes e até mesmo contrários, mas que não perdem a noção da mesma matéria e partilham da mesma bênção da semelhança divina. Não há uma prioridade. A confusão que suscita a ideia andrógina surge da essência comum dois elementos criados, partes de uma só ideia: a humanidade.

A ordem na criação também não gera conclusões de superioridade. Se entendêssemos que os primeiros seriam submissos aos últimos seres criados, entendendo o homem a coroa da criação, o ser acima de toda a criação, poderíamos supor que a mulher, criada depois dele lhe seria então superior. Colocações deste tipo não prosperam na análise do texto bíblico, porque há que se considerar o texto como um todo. Ou então, seriam os astros celestes, criados primeiros, inferiores aos mares ou os animais? É certo que a ordem não sugere algum tipo de superioridade.

Enfim, o que se vê depois da criação é uma luta constante da figura feminina pela conquista de seu espaço, luta esta que, infelizmente, ainda persiste. A necessidade de ser semelhança de Deus e não só costela.

\section{REFERÊNCIAS:}

A BÍBLIA Sagrada. Trad. João Ferreira de Almeida. São Paulo: Sociedade Bíblica do Brasil, 1958.

BÍBLIA Hebraica Stuttgartensia. 4a. Ed. Stuttgart: Deustsche Bibelgesellschaft, 1967.

BEREZIN, Rifka. Dicionário Hebraico-Português. São Paulo: EDUSP, 1995.

EVEN-SHOSHAN, Abraham. Hamilon Hechadash. 3. Ed. Jerusalm: Qryiat-sefer, 1972. 3 vol. 
FERREIRA, Aurélio Buarque de Holanda. Novo dicionário da língua portuguesa. 15a. ed. Rio de Janeiro: Nova Fronteira.

GOMES, Antonio Maspoli de Araújo; ALMEIDA, Vanessa Ponstinnicoff de. O Mito de Lilith e a Integração do Feminino na Sociedade Contemporânea. Revista âncora digital de Ciências da Religião. Disponível em: <www.revistaancoradigital.com.br $>$.

GOTTWALD, Norman K. Introdução socioliterária à Bíblia hebraica. Tradução Anacleto Alvarez; revisão H. Dalbosco. São Paulo: Paulinas, 1988.

KOLTUV, Barbara Black. O Livro de Lilith, psicologia/mitologia. São Paulo, Cultrix, 1986.

PAIVA, Vera. Evas, Marias e Liliths: as voltas do feminino. 2a. Ed., Rio de Janeiro: Brasiliense, 1993.

PLATÃO. Diálogos. Seleção de textos de José Américo Motta Pessanha. Tradução e notas de José Cavalcante de Souza, Jorge Paleikat e João Cruz Costa. 5. Ed. São Paulo: Nova Cultural, 1991. (Coleção Os pensadores). 